Palimpsesto Vol. 10, № 17 (enero-junio, 2020): 62-77

Universidad de Santiago de Chile, ISSN 0718-5898

Ernesto Sánchez Pineda

Universidad de Guanajuato

netaz16@hotmail.com

\title{
Directores que emigran: Luis Castillo Ledón y Alfonso Cravioto*
}

\section{Directors Who Emigrate: Luis Castillo Ledón and Alfonso Cravioto}

\begin{abstract}
Resumen
Este trabajo esboza la repercusión de dos personajes literarios, Luis Castillo Ledón y Alfonso Cravioto, en el ambiente cultural mexicano de comienzos del siglo XX. El recorrido historiográfico que aquí planteamos se centra brevemente en las colaboraciones de estos dos personajes en la revista Savia Moderna de 1906, pero también hace un esbozo de sus migraciones, antes y después de la empresa mostrando así que su relevancia excede las páginas de esta publicación. Es decir, el trabajo problematiza la concepción estrecha que se tiene hasta ahora de estos dos escritores y pone sobre la mesa una interpretación renovada que ayudaría a una mejor comprensión de sus intervenciones.
\end{abstract}

Palabras claves: Ateneo, México, Literatura, Intelectual, Siglo XX.

\begin{abstract}
This work outlines the repercussion of two figures in the Mexican cultural ambient: Luis Castillo Ledón and Alfonso Cravioto. Both writers associated with Savia Moderna (1906). The provided historiographical background centers in the collaborations of these two characters in the magazine, but it also outlines their migrations, before and after of the enterprise, showing that their relevance in the cultural Mexican panorama exceeds the pages of this enterprise. That is to say, this essay problematizes the narrow conception that we have of these two writers and put over the table a new interpretation that will help to understand better their interventions.
\end{abstract}

Keywords: Ateneo, México, Literature, Intellectual, 20th century.

\footnotetext{
* Este artículo se realizó en el marco de una Estancia Posdoctoral en el programa de posgrado de Maestría en Literatura Hispanoamericana de la Universidad de Guanajuato, apoyada por el Consejo Nacional de Ciencia y Tecnología.
} 
Hay asociaciones que de tanto repetirse se han fijado de manera casi indiscutible en la historia de la literatura mexicana. Evocaciones de nombres que llevan el pensamiento a un espacio, un libro o una revista o, al contrario, reminiscencias de eventos, lugares o periódicos que remiten inmediatamente a los personajes involucrados. Uno de esos casos es el de Alfonso Cravioto y Luis Castillo Ledón, escritores cuya sola mención enfoca naturalmente la mirada del curioso y del investigador en uno de sus proyectos juveniles que se ha establecido con el tiempo como el punto de partida para el estudio del Ateneo de la Juventud: la revista Savia Moderna (1906).

Sin embargo, el proyecto de esos años mozos sólo es una parte, importante sí, de las acciones en las que estos escritores se vieron involucrados a lo largo de su vida. Y las implicaciones que resultan de estas participaciones todavía están por registrarse. Por eso, lo que comparto aquí, es un esbozo de de las trayectorias de estos provincianos en el mundo de las letras, en los espacios públicos y en el acontecer histórico-literario mexicano, haciendo énfasis en sus colaboraciones en la Savia Moderna y las migraciones que tuvieron que suceder para que esta empresa cobrara vida, pero también señalando otras migraciones después de esta empresa que, por ahora, sólo esbozan la complejidad de las carreras de estos escritores.

Fernando Curiel Desoffé registra que Luis Castillo Ledón nació el 17 de enero de 1879, en la villa de Santiago Ixcuitla, en lo que hoy es el estado de Nayarit. Cinco años después, el 24 de enero de 1884, en la ciudad de Pachuca, Hidalgo, nació Alfonso Cravioto Mejorada (Curiel Defossé, 2001, pp.20-30 y pp.35-36). La diferencia de cinco años, a lo lejos, parece casi imperceptible; sin embargo, tiene repercusiones en la experiencia que antecede el momento en que ambos jóvenes se conocieron, pues aunque los dos incursionaron en el ambiente literario de manera precoz, los espacios desde los cuales lo hicieron y las experiencias que acompañaron dicha incursión estuvieron marcados por diferentes matices, que, a pesar de tiempo, fueron significativas en la construcción de sus personalidades públicas.

De Castillo Ledón sabemos, gracias al estudio monográfico Luis Castillo Ledón (18791944), de Savio a historiógrafo ateneista 1906-1911 de Julieta Ávila Hernández, que junto con algunos de sus compañeros de escuela, dirigió un par de periódicos por los años de 1896 y 1897 , llamados El Reporter y Pierrot, aunque también se le atribuye otro de su etapa adolecente llamado El Chiquitín, época en la que escribió un primer libro de poesía intitulado De Crisálidas (pp.14-15). En este estudio, la investigadora desmiente que exista otro periódico titulado Casi de juguete, y atribuye la confusión a una entrevista que se realizó al ateneísta, donde éste habla de un proyecto que pensó realizar en su juventud. Ahora bien, más tarde, cuando migró a Guadalajara, Castillo Ledón trabajó en La Gaceta de Guadalajara; y "estableció relaciones con las siguientes ediciones: La Libertad, Juan Panadero, La Suegra, El Bien Público, Revista Blanca, Buena Sombra, Negro y Rojo", El Sol y, después, en 1903, sería dueño y director de El Monitor de Occidente (Cf. Ávila Hernández, 2010, pp.17-18).

Todavía en Guadalajara, comenzó a estudiar en el Liceo de Varones, donde tuvo como uno de sus maestros más cercanos a Victoriano Salado Álvarez, personaje de una relevancia substancial por su involucramiento en las polémicas finiseculares de fin de siglo, las cuales tuvieron repercusiones tanto en las concepciones poéticas de la época como en los grupos literarios que se formaron a partir de la discusión en torno a ello. Para todos los escritores de 
principios del siglo $\mathrm{XX}$, incluidos los ateneístas, tomar partido se presentó como una disyuntiva entre el gusto personal y la conveniencia político-literaria que podría implicar la decisión. ${ }^{1}$ Ahora bien, la amistad entre Castillo Ledón y Salado Álvarez es un ejemplo de estas afinidades que muchos de los ateneístas tuvieron con personajes representativos de fines del siglo XIX que defendían una estética ajena a la del modernismo, movimiento poético preponderante en Hispanoamérica. ${ }^{2}$

Por otro lado, también fue en el Liceo de Varones donde Castillo Ledón hizo migas con José María Sierra, un joven de su edad con quien estableció una mancuerna que no tardó en consolidar su posición en el ambiente literario de Guadalajara, al encabezar la mesa directiva de la Sociedad Literaria "Manuel Gutiérrez Nájera" en 1901; año en que Castillo Ledón publicó un poema por primera vez en un periódico capitalino, El Imparcial (Ávila Hernández, 2010, p.1819).

La aceptación que tuvo el nayarita en Guadalajara fomentó su entusiasmo por los proyectos editoriales; más aún, gracias a la minuciosa investigación del archivo de Castillo León hecha por Julieta Ávila Hernández, se puede establecer que fue en tierra tapatía donde germinó la idea de publicar Savia Moderna y no en Hidalgo, con Alfonso Cravioto, como suelen apuntar la mayoría de los críticos:

José María Sierra, autor, al igual que Tablada, de una Misa Negra, [...] escribió a Luis Castillo, con la siguiente fecha: Jul 281903 [...] El sábado próximo aparecerá Pist!!... periódico que vamos a fundar entre Carpio, Luis Quevedo y yo. Se ocupará sólo de guasas y de teatros. Esperamos sacar dinero de él para después fundar nuestra tan soñada "Savia Moderna". (p.20)

Después de este preámbulo literario, marcado por empresas efímeras y de espíritu juvenil, ocurre la segunda migración del director provinciano. El nayarita llegó a la Ciudad de México por consejo del poeta Amado Nervo, que lo vinculó directamente con la crema y nata de la intelectualidad mexicana, la cual solía congregarse en la casa del mecenas y director de Revista Moderna de México, Jesús E. Valenzuela. Tanto Nervo como Valenzuela eran representantes del modernismo finisecular, movimiento literario que postulaba una poética opuesta a la procurada por Salado Álvarez, mentor en provincia de Castillo Ledón, lo cual muestra la habilidad de Castillo Ledón para manejarse en diferentes círculos literarios y, al mismo tiempo, refuta la idea que las facciones encontradas en las polémicas finiseculares fueran tan cerradas como se suele plantear en nuestra historiografía literaria.

La casa de Jesús E. Valenzuela fungió como un epicentro para las personalidades del ambiente literario finisecular; ahí, confluían destacados representantes de distintas corrientes literarias, los cuales habían encontrado en las páginas de su revista un espacio que, a pesar de

\footnotetext{
${ }^{1}$ No por nada, Belem Clark de Lara y Ana Laura Zavala Díaz en su libro La construcción del modernismo (2002), y Juan Pascual Gay en El beso de la quimera abordan estas polémicas de 1893 y 1896 como eventos decisivos en la conformación literaria finisecular.

${ }^{2}$ José Miguel Oviedo lo caracteriza en Hispanoamérica como una combinación de movimiento literarios europeos, principalmente del Art Nouveau que era "agudamente estilizado y ornamental [...] la nueva tendencia subrayaba la artificialidad del arte: sus figuras planas y frontales, el esmaltado y los arabescos para crear ambientes suntuosos y encantados"; pero advierte, también, que "tampoco hay que creer que en Hispanoamérica el modernismo es una estética aislada y de indiscutida hegemonía. [...] se mantuvo en una lucha constante con los seguidores de otras tendencias del momento - particularmente del realialismo y el naturalismo-" (2001, pp.223-225).
} 
algunas restricciones estéticas y políticas, mostró a las mejores plumas del momento. Justo en estas famosas reuniones, las cuales rebozaban de suntuosidad y camaradería, empezaban a figurar los nombres de algunos personajes pro-ateneístas, como los llama Fernando Curiel, una pléyade que comenzaba a dar muestras de sus talentos en los albores del siglo XX. De estos primeros personajes se mencionan en diferentes notas periodísticas de El Diario del Hogar, El País y El Tiempo Ilustrado a Roberto Argüelles Bringas, Ricardo Gómez Robelo, Enrique González Martínez, Rafael López, Manuel de la Parra, Efrén Rebolledo, Abel C. Salazar, Luis G. Urbina, Jesús Urueta, y Ángel Zárraga (Cf. Curiel Defossé, 1996, pp.39-59). Vicente Quirarte, por su lado, apunta que esto se debe a que Valenzuela era "un hombre de dos reinos, un puente entre dos generaciones" (2001, p.17); mientras que Max Henríquez Ureña, lo recuerda como: "mecenas, y se significó como lazo de unión entre los hasta entonces dispersos representantes de las nuevas tendencias" (1978, p.465).

En ese espacio donde la literatura cobraba vida y las relaciones entre los escritores se fortalecían, es donde sospecho que Luis Castillo Ledón conoció al joven Alfonso Cravioto, que ya por esas fechas había llegado a la capital. No obstante, hay que apuntar que el cobijo de Amado Nervo para el nayarita no cesó ahí, pues a su regreso a México también lo ayudó a obtener un puesto en la Biblioteca Nacional, hecho que estableció la pauta de su desarrollo personal, donde se desempeñó como secretario de José María Vigil en 1903 (Ávila Hernández, 2010, p.22).

En 1904, Castillo Ledón “participó y triunfó en un popular y todavía prestigioso concurso literario: los Juegos Florales. El archivo ALCL (Archivo Luis Castillo Ledón) guarda un documento: [titulado] Minerva, el número único del Órgano de la juventud estudiosa, en el que se da cuenta de las cuatro composiciones premiadas en los juegos potosinos de septiembre de 1904" (Ávila Hernández, 2010, p.21) donde obtuvo el segundo lugar. En el mismo certamen, Cravioto también fue galardonado, desde ahí los caminos de ambos parece que están destinados a seguirse cruzando.

Sin embargo, si el nayarita da muestras de interés por la literatura y los diferentes medios de publicación, las primeras incursiones de Alfonso Cravioto Mejorada, aunque similares, muestran una clara diferencia: el interés por la política.

Cravioto formó parte de la familia más poderosa del estado de Hidalgo. Su estatus social le proveyó de privilegios infantiles a los que pocos pueden aspirar, como las clases particulares y una gran biblioteca a su entera disposición. A los once años, en 1895, ingresó al Instituto Científico Literario que en ese entonces dirigía Baltazar Muñoz Lumbier, un crítico mordaz del régimen porfiriano. Es probable que ahí se fortalecieran las ideas liberales que había cultivado en su niñez, pues como él recuerda:

[...] mis mejores amigos les tenía entre las clases pobres. Llegamos a formar una pandilla como de 50 muchachos que [...] nos reuníamos [y] formamos un "partido liberal" en contra de otro núcleo formado por "mochos" y cada jueves concertábamos guerras a pedradas con nuestros enemigos. Una vez estuve en cama durante ocho días por una pedrada que recibí en una pierna [...]. (Cravioto Apud Granados Chapa, 1984, p.27)

En 1898, el gobernador del estado de Hidalgo, Ignacio Nieva, no celebró el aniversario de la muerte de Benito Juárez, "Benemérito de las Américas" e ícono de la facción liberal en México; el acto provocó que los inconformes se reunieran y organizaran su propio homenaje, y 
después se constituyeran como la Corporación Patriótica Privada, que fue el "núcleo aglutinador del liberalismo hidalguense", y "que se expresaban por medio de un periódico, El Desfanatizador", donde el joven Alfonso Cravioto fungió como director. En este semanario, fundado por Francisco de Paula Castrejón Escobar, el joven dio muestras de sus habilidades para dirigir una empresa literaria durante treinta y nueve números, mientras estudiaba en el bachillerato en el Instituto Científico Literario, en lo que hoy es la Universidad Autónoma de Hidalgo. También, por esas fechas, comenzó a colaborar en El Hijo del Ahuizote (1885), ${ }^{3}$ dirigido por Daniel Cabrera Rivera, Manuel Pérez Bibbins y Juan Sarabia, pero que después, entrado el siglo XX, en 1902, pasó a manos de los hermanos Flores Magón (Granados Chapa, 1984, pp.3031). También hay que recordar que el general Rafael Cravioto fue gobernador del estado de Hidalgo, poder que compartió con dos de sus hermanos desde 1877 hasta 1897, cuando, electo por cuarta ocasión, el general tuvo que renunciar por presiones del presidente Porfirio Díaz (Cf. Cravioto, 2009, pp.205-240).

A pesar de las afiliaciones políticas de su linaje, a los 16 años de edad, Alfonso Cravioto firmó junto con Mariano Lechuga una protesta por la violenta disolución de una manifestación estudiantil en honor a Benito Juárez, la cual se reproduce en el periódico Regeneración de los hermanos Jesús y Ricardo Flores Magón: ${ }^{4}$

Protesta: No nos sentimos impulsados por un arranque noble de compañerismo o por un empuje fanático de igualdad de ideales, no, nosotros venimos a lanzar nuestra protesta contra el encarcelamiento de unos estudiantes dignos en nombre de la civilización ultrajada en nombre de justicia encarnecida, en nombre de la Libertad pisoteada, en nombre de la Patria y en nombre de JUÁREZ del GRAN JUÁREZ que en su tumba se yergue palpitante de irritación señalando con su índice broncíneo las cabezas de dos analfabetas del deber, de los usurpadores de libertades, de dos parias de la civilización que quieren borrar, a fuera de cerrojos su infamante conducta ya estampada en las páginas negras de la historia [...]. (Cravioto/Lechuga, p.50)

Este documento refleja tanto la inconformidad como la beligerancia característica de una juventud que buscaba a gritos ser escuchada, pero, sobre todo, adquiere relevancia porque tendrá eco en lo que podría considerarse el manifiesto del grupo ateneísta seis años más tarde. ${ }^{5}$ Sobre ello apunta Arturo Vergara Hernández, que:

Mariano Lechuga y Alfonso Cravioto escribieron una carta de protesta impresa en un volante, fechada el 4 de agosto de 1901, en la que manifiestan su repudio al jefe político de Pachuca Antonio Grande Guerrero y al mayor Carlos G. Pacheco, ejecutores de la represión y las aprensiones. A raíz de esto, y sobre la base de sus influencias, el Lic.

\footnotetext{
${ }^{3}$ La revista fue de corte satírico y estuvo desde un principio en contra del régimen porfirista, de quien hacía críticas por medio de caricaturas y textos humorísticos.

${ }^{4}$ Regeneración fue un periódico anarquista que se dedicó a atacar constantemente la dictadura de Porfirio Díaz, su talante era combativo y provocó que muchos de sus colaboradores fueran perseguidos políticamente, apresados o mandados al exilio. Los hermanos Flores Magón, sus directores, son precursores ideológicos de la Revolución mexicana que comenzó en 1910.

${ }^{5}$ En otros textos, he tratado de plantear que la "Protesta literaria" serviría como manifiesto de los ateneístas, pues reúne las características más esenciales de éstos (Cf. "La Revista Azul", pp.99-115 y "La toma de un espacio", pp.239-258).
} 
Ignacio Urquijo consiguió una mejoría en el trato hacia los estudiantes presos y luego su libertad, aunque todavía tardaron en liberar al maestro Noble. (2011, pp.12-13)

La redacción de Regeneración aplaudió a los jóvenes y los justificó puesto que "el atropello ha sido infame. Por eso la juventud que no soporta humillaciones se ha alzado airada y ha conmovido a la Nación con su heroica actitud" (Vergara Hernández, 2011, pp.12-13). En otro artículo, fechado el 31 de agosto de 1901, se vuelve a manifestar el apoyo a los jóvenes que firmaron la protesta:

¡iHACEMOS NUESTRAS LAS PROTESTAS DEL 22 DE JULIO Y LA DEL 4 DE AGOSTO, FIRMADA POR LOS SEÑORES LECHUGA Y CRAVIOTO!!! [...] Nos complace ver el sentimiento de solidaridad de Hidalgo, sentimiento que quisiéramos ver también en los del Distrito Federal y en los de toda la República, para no permitir que cualquier déspota valido de su cargo oficial, haga burla de los derechos que otorgan nuestras instituciones liberales. Aplaudimos la actitud de tan dignos jóvenes porque saben hacerse respetar. (Varios, Regeneración)

En otra entrada, dirigida al público, se reproduce un discurso pronunciado por Alfonso Cravioto, donde habla de sus profesores y guías: el licenciado Urquijo, el profesor Navarro y Muñoz Lumbier; de este último apunta:

Y vos, al luchar contra los fuertes, al defender una causa justa pero erizada de peligros, no erais el simpatizador de una juventud noble; no erais fanático arrebatado por la sublimidad de un ideal; erais la Justicia, la misma Justicia que besaba la frente de una juventud grande porque es libre, fuerte porque piensa. (S/f, "Al público")

No obstante, a pesar de las múltiples empresas en las que estaba involucrado en Hidalgo (o quizás por ellas mismas y la presión familiar por abandonarlas) en 1902, Cravioto llegó a la Ciudad de México para proseguir con sus estudios en la Escuela de Jurisprudencia. El provinciano apasionado de las letras y la política emprendió su primera migración hacia la ciudad. Aparentemente, en la capital podría encontrar un ambiente políticamente más bullicioso; sin embargo, el temple revolucionario de Cravioto destaca tanto que de inmediato se afilia a la agrupación estudiantil Ignacio Ramírez de la cual es electo presidente unas semanas más tarde. A pesar de ello, apunta Miguel Ángel Granados Chapa, el ámbito capitalino "es reducido para el afán libertario de Cravioto, quien frecuenta a los hermanos Flores Magón, con quienes había entablado relación en los días agitados de 1901, [por eso acude] a la reinstalación del club liberal Ponciano Arriaga, el 5 de febrero de 1903" (p.32), donde fungió como vocal; la mesa directiva de este organismo se conformó por: Camilo Arriaga, presidente; Antonio Díaz Soto y Gama, vicepresidente; Benjamín Millán, tesorero; Juan Sarabia, primer secretario; Ricardo Flores Magón, segundo secretario; Santiago del a hoz, tercero; vocales: Juana B. Gutiérrez de Mendoza, Evaristo Guillén, Federico Pérez Fernández, Rosalío Bustamante, Elisa Acuña y Rosete, Alfonso Cravioto, Srta. Refugio Vélez, Salvador Soto, Tomas Sarabia y Alfonso Arcienega (Granados Chapa, 1984, p.32).

Tal vez por estar acostumbrado a las muestras más radicales que se hacían en provincia, pertenecer a la agrupación estudiantil Ignacio Ramírez no fue suficiente para el pachuqueño; por 
lo mismo, no sorprende que en seguida se afiliara al Club Antirreeleccionista Redención, ${ }^{6}$ del que fue vicepresidente, el cual operaba y se manifestaba públicamente de una manera más radical que la agrupación estudiantil. La postura siempre combativa de Cravioto le dio la oportunidad para participar en diferentes publicaciones de época, principalmente de corte antirreeleccionista; su presencia es vasta, como lo prueban sus incursiones en El Colmillo Público, dirigida por Jesús Martínez Carrión; El Partido Democrático y El Radical, que estaban a cargo de Jesús Urueta, y Vésper, de Juana B. Gutiérrez de Mendoza (Cravioto, 2009, p.208). Ahora bien, el manifiesto del Club Antirreeleccionista Redención se publicó en El Hijo del Ahuizote donde también se insertó un poema de Cravioto que no se incluye en el tomo de sus poesías completas, pero que Miguel Ángel Granados Chapa reproduce íntegro (pp.35-36). Del mismo modo su presencia pública fue en aumento, pues participaba en manifestaciones antirreeleccionistas que tomaban como pretexto algún evento realizado por el régimen porfirista para alzar la voz y dar su opinión, estrategia que los jóvenes proto-ateneístas iban a seguir empleando antes de estar conformados como grupo y también después. Granados Chapa apunta que

De manera semejante a como el cinco de febrero anterior los liberales aprovecharon la efemérides para proclamar "¡la constitución ha muerto!”, resolvieron montarse en una manifestación en pro de Díaz, provista para el Dos de Abril (que era la fiesta porfírica por excelencia, luego del 15 de septiembre, coincidentemente día del cumpleaños de la patria y del dictador) para hacer una contramarcha antirreeleccionista. (p.36)

Esta idea también la comparte Arturo Vergara Hernández, cuando apunta que "los liberales radicales empezaron a utilizar las fiestas cívicas y el nombre de los próceres nacionales con un contenido y una intención distinta, que al tiempo que rebasaba el tratamiento oficial constituía un arma para señalar los errores del gobierno" (Vergara Hernández, 2011, p.9). Es decir, "Utilizaron el nombre de Benito Juárez como bandera ideológica para reprochar a Díaz su perpetuación en el poder, ya que éste se había opuesto a la reelección del benemérito con el llamado plan de Tuxtepec" (Vergara Hernández, 2011, p.9).

No es de extrañar que esta actitud combativa, en un gobierno opresor como el de Díaz, condujera a Cravioto a la cárcel en abril de ese año (Vergara Hernández, 2011, p.40), de donde salió sólo para acompañar a su padre en el lecho de muerte. Al momento de su arresto, se pronunciaron sus compañeros en El Hijo del Ahuizote:

El público comprenderá, que cuando hablamos de recua, no aludimos a agentes de la autoridad en ejercicio de sus funciones; pero Emilio Álvarez quiere que sea así, ofendiendo con sus alusiones a los señores Magistrados del Tribunal Pleno.

¡Y después de hacer esa alusión sangrienta, nos acusa y nos encarcela!

Se encuentran presos en la cárcel de Belem los señores Juan Sarabia, Ricardo y Enrique Flores Magón, Alfonso Cravioto y Santiago R. de la Vega.

Nuestros compañeros presos han sido objeto de las mayores vejaciones.

A nuestros compañeros les ha impedido hablar con sus defensores, dizque por orden Superior, violando la Constitución a su capricho. Ha dado orden de que SOLAMENTE

\footnotetext{
${ }^{6}$ Estos grupos tenían una ideología liberal, tanto en el aspecto social como en el económico, pero su base principal era la idea de no relección a la presidencia y otros cargos políticos, en este caso de Porfirio Díaz.
} 
EL MARTES DE CADA SEMANA puedan entrar los defensores a hablar con nuestros compañeros.

El Hijo del Ahuizote protesta contra los arbitrarios procedimientos de Oscuras, propios para un país de cafres y no para dar lustre a nuestra infortunada patria.

La Constitución ampara a los presos de toda molestia y ya diremos en nuestro próximo número todas las vejaciones de que son objeto los presos en la Cárcel de Belem, para que se tenga una idea de lo mal que desempeña Oscuras su oficio de cancerbero.

Todo esto lo hacemos por interés público, porque es penoso que en México se empleen en las cárceles procedimientos inquisitoriales y alusivos. ("Nuestros compañeros en Belém”, pp.234-235)

Este evento marcaría profundamente al joven de tan sólo 19 años. Sobre ello, apunta Granados Chapa: "a la muerte de su padre, uno de los fuelles que alimentaban sus fuegos interiores dejó de soplar. Y cuando en 1905 el magonismo se abrió a la definición anarquista que en verdad alentaba, Cravioto, que era un liberal, abrió paréntesis en su militancia política” (p.45). Fue una etapa en que el pachuqueño se volcó a las letras, prueba de ello fue su participación en los Juegos Florales ya mencionados donde coincidió con Castillo Ledón.

1905 fue un año decisivo, pues si Cravioto se distanció de los avatares de la política arremetió, gracias a la herencia que le dejó su padre, desde otro frente: la literatura. La idea de una revista fraguada por Luis Castillo Ledón y José María Sierra bajo el nombre de Savia Moderna, tenía ahora el respaldo económico para tomar forma y consistencia. Y aunque una de las labores cardinales que se le adjudican a Alfonso Cravioto en los inicios de esta empresa es que se lanzara a la búsqueda de nuevos talentos literarios, la presencia de colaboradores de provincia ya era vasta, es por eso que antes de iniciar el año de 1906 Savia Moderna tuviera una nómina casi establecida.

La primera migración de estos escritores, de provincia a la ciudad, encontró su punto álgido en la creación de Savia Moderna pues, aunque tanto el nayarita como el pachuqueño ya habían encabezado empresas literarias, fue el primer proyecto capitalino que dirigieron. Además, la empresa se insertaba en un ambiente convulso tanto en lo político como en lo literario, lo que probablemente exigió a los directores explotar todas las habilidades que habían adquirido en provincia para que su empresa no pasara desapercibida.

La atribución de la idea de esta empresa a Cravioto, por parte de la mayoría de los investigadores, se justifica porque sin el apoyo financiero que él propició tal vez ésta nunca hubiera existido. Simplemente para que esta empresa comenzara, Cravioto rentó el despacho número 32, en el quinto piso del número 88 de la primera de Cinco de Mayo (hoy Avenida 5 de mayo). Al edificio se le llamaba La Palestina (que era el nombre del negocio que ocupaba la planta baja de la construcción de cinco pisos). La recién heredada fortuna le permitió decorarlo de manera elegante e incluso lujosa, contrastando con los espacios donde se editaban otras publicaciones periódicas. "De un lado se ve la Catedral y del otro los crepúsculos de la Alameda. El piso del edificio es de mármol. Abajo corren cafés, bares, tiendas, librerías. "Aquello era un Areópago, un Parnaso, un palacio, una corte de los Medicis', recuerda Jesús Villalpando" (Mauleón, 2006). Estampa totalmente contradictoria a la que recuerda Rafael López: "La redacción era pequeña como una jaula [...] Algunas aves comenzaron allí a cantar." Una de esas aves fue Alfonso Reyes, que recuerda cómo su camino se cruzó con la publicación en ciernes: 
Pisaba yo las últimas gradas de la Preparatoria y, a falta de mejor cosa, me disponía para la carrera de Derecho, procediendo por aproximación, cuando aconteció mi verdadero acceso a la vida literaria. Un poeta potosino, José María Facha, un sobrino de Othón, que había obtenido en Monterrey su título de abogado porque creo lo desterró de San Luis su inquina contra monseñor Montes de Oca, apareció unos días por México. Aunque mayor que yo, éramos buenos amigos. Salimos a pasear juntos el domingo por la mañana, a la moda de entonces, por la Avenida de San Francisco y Plateros. Nos encontramos con uno de los más oscuros colaboradores de una revista juvenil que iba a lanzarse por esos días, y él nos invitó a visitar a los poetas que a esa hora se reunían en la redacción.

Yo había contemplado con envidia y anhelo los anuncios de la tal revista, Savia Moderna, algo como una hija de la célebre Revista Moderna, aún viva y operante por obra y gracia de don Chucho Valenzuela y los últimos modernistas; pero distaba mucho de figurarme que pronto me sería posible ingresar en sus filas; me daba cuenta de que era demasiado temprano. Nos encaminamos a la Avenida del Cinco de Mayo, donde estaba la redacción de Savia Moderna, cuyo director efectivo era Alfonso Cravioto. Cravioto se apartó conmigo. Había figurado tiempo atrás en ciertos actos de oposición contra el gobierno de mi padre, y eso mismo - como hombre bien intencionado que es - lo hizo desear conocerme y mostrarse afable. A poco, ya publicaba yo mis renglones tanto en esta revista como en la de Valenzuela, con quien pronto me relacionó su hijo Emilio. (1960, p.202)

Las migraciones de los directores de provincia a la capital propiciaron que otros jóvenes escritores se agruparan en el recinto ubicado en la Cinco de Mayo. Desde ahí, Cravioto impulsó un proyecto que a la distancia puede parecer efímero en la historia de la literatura mexicana pero que fue crucial para que el grupo ateneísta se conformara. La importancia de este primer espacio de convivencia es tal que la mayoría de las investigaciones acuden a él para explicar la génesis del grupo. Aunque hay que enfatizar que las raíces del grupo no se desprenden necesariamente de lo que ocurrió en este espacio, sino a una serie de sucesos que, como veremos adelante, determinaron el carácter que después distinguió al Ateneo.

Es importante anotar que, como Fernando Curiel Defossé registra (1996, pp.44-48), algunos de los integrantes de Savia Moderna ya contaban con experiencia colaborando en Revista Moderna de México mientras que otros eran nóveles que encontraron en ese nuevo espacio la oportunidad para dar a conocer su nombre. Sin embargo, por considerarse el punto de partida en las investigaciones del Ateneo de la Juventud, los estudios que giran sobre Savia Moderna son abundantes. Acaso convenga sólo añadir un par de puntos que ayuden a seguir la pista de los directores que la pusieron en marcha.

Entrando el año de 1906, en el diario El Presente, sale un anuncio que promociona la nueva publicación: "Savia Moderna es el título de una revista semanaria ilustrada que aparecerá en esta capital el 30 de enero y será dirigida por los conocidos poetas Alfonso Cravioto, Luis Castillo y José María Sierra". La forma en que los nombres están dispuestos en el anuncio no es gratuita, se le atribuía más importancia al papel de Cravioto sobre los otros dos escritores.

Susana Quintanilla nos proporciona una descripción general del formato de la revista, la cual comenzó con una periodicidad mensual y un costo de 50 centavos. Las entregas constaban de 58 a 64 páginas y contaba con cubiertas de cartulina, de diferente color en cada número. La portada del primer número fue la reproducción de un óleo de una mujer semidesnuda tocando un arpa con motivos griegos del artista catalán Antonio Fabrés, mientras que las portadas siguientes 
fueron ilustradas por la reproducción de un dibujo al carbón de Diego Rivera, que mostraba el torso de un corredor indígena. Savia Moderna incluyó los siguientes anuncios publicitarios a lo largo de sus cinco números: La Palestina [Peletería y Herrajes], WM. A. Parker [Máquinas de escribir], José María Lupercio [Fotografía], La Kalodermina Imperial [Crema, anuncio de José María Castillo Ledón, hermano del director de la empresa], Sierra y Fernández [Electricistas], Emulsión de Scott, Tabacalera Mexicana, Casa Importadora, Ingeniero A. San Juan [Hidráulica], Ingeniero José E. Cacho [Hierro] y La Fraternal [Seguros]. La Investigadora también apunta que la revista era vendida en las librerías: Viuda de Charles Bouret, Maurice Gillot, Librería Madrileña, Andrés Botas, Maucci Hermanos y Ramón Araluce (Quintanilla, 2008, p.288).

También, gracias al trabajo de archivo realizado por Ávila Hernández, se cuenta con una carta de José B. Velazco, fechada el 29 de enero de 1906, felicitando a Castillo Ledón: "Fue una gran alegría saber que el proyecto acariciado por Ud. tanto tiempo, va al fin a realizarse" (2010, pp.24-25). La investigadora habla también de

un díptico publicitario, editado, de igual modo, por los jóvenes impulsores de la revista y realizado por la tipografía de I. Escalante, misma a la que también habían recurrido los de la Revista Moderna. Del díptico ya he hecho algunas apreciaciones. [...] Como en 1905 no se halló en la ciudad de México ninguna alusión expresa a la revista, el folleto promocional, los datos de El Presente y la carta de Velasco, me permiten reconocer que, al menos, para enero de 1906 ya se había comenzado a organizar la edición de Savia Moderna; el directorio estaba, todavía, en proceso. (2010, p.27)

La investigadora analiza más a fondo dicho díptico en "Savia Moderna. Frontera entre siglos" (pp.265-277), pero estas líneas bastan para cuestionar y reconsiderar el papel casi único que la crítica a otorgado a Cravioto como creador, vamos a decir intelectual, de la revista.

Por otro lado, las colaboraciones de los directores en su propia publicación son pocas. Castillo Ledón contribuyó con tres poemas y un apartado que contiene cuatro reseñas; Cravioto participó con tres poemas y una esquela. Los poemas del primero, "Amor-materia", "La familia joyeuse" y "Presentimiento" muestran un apego a la escuela modernista tanto en el manejo de la forma como de los temas. Por ejemplo, en el primero de ellos aparece un estereotipo de la figura femenina, muy divulgada a finales del siglo, que oscila entre la seducción y la perdición, entre la inocencia y la perdición: "Y si tu boca quiere, en su denuedo,/ brindarme su dulzura,/ de ti me aparto porque tengo miedo/ el vértigo sentir la locura!" (p.44). Los poemas de Cravioto, "invocación", "El dolor" y "Sensaciones de viaje", no se alejan demasiado de estas temáticas, pero también se inclinan hacia la reflexión filosófica impregnados de cierto pesimismo característico de los pensadores alemanes que fueron autores de cabecera de los ateneístas: Schopenhauer y Nietzsche; como se puede apreciar en los primeros versos de "El dolor": "Triste y solo recorriendo voy la senda aridecida/ donde tienden las angustias sus abrojos por alfombra;/ donde erispan su amenaza los zarzales de la vida; donde hay ríos que son llanto; donde hay savia maldecida/ que produce eternamente sólo cálices de sombra" (p.115).

Los poemas de los directores no contradicen lo que se ha dicho sobre Savia Moderna como una emulación directa de Revista Moderna de México en cuanto su contenido literario; tampoco lo hacen las colaboraciones en prosa, pero éstas presentan una visión particular de los escritores sobre el acontecer literario, pues señalan enfáticamente ciertas afinidades y admiraciones que van más allá de la literatura y cruzan a la acción pública de aquellos a los que se refieren. 
De las cuatro reseñas de Castillo Ledón, la primera versa sobre Almas que pasan de Amado Nervo, donde el nayarita no se limita en su admiración por Nervo y lo compara con Gutiérrez Nájera, llegando a afirmar "y si no lo supera en delicadeza, sí tal vez le gana en cultura y corrección" (p.219). La segunda reseña tiene como motivo el Homenaje de la Revista Occidente de Guadalajara a José Ortiz Vidales. Ahí Castillo Ledón hace un recuento de su propio papel como director de revistas literarias en tierras provincianas, recuerdos en sepia donde se presenta a sí mismo alejado ya de la imagen de pupilo bajo las alas de Salado Álvarez y Nervo y se coloca como una figura capaz de introducir a un escritor en el ambiente literario: "Aún recuerdo que fui yo quien, a su arribo a Morelia [...] introduje a la vida intelectual de aquel centro, lo relacioné con poetas, periodistas y pintores, y le publiqué en El Monitor Occidental, los primeros versos" (p.220). La reseña de La Siega, una novela de Rafael Ceniceros y Villarreal, tiene poca relevancia, pero la que hace sobre Celajes, versos de Jesús Romero Flores, devela que su elección por una poética modernista es consciente y no una imitación juvenil descuidada, algo de lo que acusa al escritor que reseña: "El autor de este pequeño libro es un adolecente. No sigue un rumbo fijo, ni es tiempo todavía que lo tome. Tiene mucho de todos y casi nada de él" (p.221), y qué no son las producciones poéticas de estos dos directores sino ecos de aquellas de los grandes modernistas que tanto admiraban.

Por otro lado, en ese mismo cambio de dirección que distingue las colaboraciones en prosa de los directores de Savia Moderna, no extraña que en el panegírico que Cravioto escribe a la muerte de Baltazar Muñoz Lumbier devele, más allá de su admiración por el maestro de la juventud en Hidalgo, cierta comunión ideológica: "Nació demagogo en la más respetable acepción de esta discutidísima palabra. No entendió la política como 'el arte de disfrazar de interés general el interés particular"' (p.66). Por otra parte, en el panegírico, Cravioto señala algunas actitudes y concepciones políticas de su maestro que él mismo cultivó: "Aprendió con el filósofo britano, que el valor de un Estado no es otra cosa que el valor de los individuos que lo componen; y en toda su vida pública se ve la tendencia a dignificar y levantar el espíritu de sus conciudadanos" (p.66), actitud que fue una de las principales directrices de los ateneístas.

A la par de las breves colaboraciones, hay otra faceta, más técnica, que muestra cómo trabajaron los directores de la revista. Si bien estaban comprometidos con la empresa ésta se publicó de forma irregular, retrasándose en sus entregas. Los motivos no fueron económicos, sino organizativos, y reflejan que, a pesar de la experiencia de ambos directores en empresas previas, Savia Moderna resultó ser una tarea, en orden práctico, que exigía más de lo que ellos estaban acostumbrados a entregar en provincia. Y cuando Cravioto partió a Europa, en una migración que se ha considerado la causa del cierre de la revista, Castillo Ledón quedó sólo en la dirección, pues ni siquiera contó con la ayuda de José María Sierra, que tenía una tendencia a la depresión y buscaba los "rumbos de la vulgaridad y la muerte', de la parranda y el alcohol" (Ávila Hernández, 2010, p.48). Sin embargo, Cravioto exigía, a pesar de la distancia, cierta calidad en la revista, mientras Castillo Ledón hacía lo posible por mantenerla a flote. Por eso agrega a Roberto Argüelles Bringas como secretario de redacción y después, a partir del cuarto número, a Pedro Henríquez Ureña. Y aunque toda decisión se consultaba a distancia con Cravioto, la responsabilidad recaía, a final de cuentas, sobre el nayarita, que para ese entonces obtuvo una nueva carga de actividades por parte de la Biblioteca Nacional, pues fue nombrado encargado del Boletín y de Publicaciones Anexas (Ávila Hernández, 2010, pp.58-70). Hay que apuntar que Ávila Hernández registra también un deseo por parte de Cravioto para sacar una versión española de Savia Moderna que nunca se concretó: 
Dichos planes fueron expresados [...] a Luis Castillo en los siguientes términos: Tenemos el proyecto de hacer una edición de Savia Moderna aquí, este número será probablemente el de septiembre si logramos vencer algunas dificultades que hay. Contamos con todos los mexicanos artistas que hay en Europa, así como Nervo e Icaza. Creo que este número hecho con insuperables elementos tipográficos resultará sensacional y con la originalidad de ser el primer intento periodístico que se haga en Europa por mexicanos. Entre todos nosotros hay interés y entusiasmo por trabajar en ese número de Savia que indudablemente aumentará el prestigio de nuestra Revista. [...] Pensamos hacerlo a varias tintas y en papel opaco. El material además de la parte de verso estará formado por impresionismos y estudios del arte francés moderno y notas sobre el estado actual de la música, de la literatura y el teatro. Creo que con todo esto saldrá variado, instructivo y ameno. Esperemos que este número tenga éxito y si este es suficiente, no es difícil que establezcamos en París una edición europea de Savia Moderna. Realizaremos esto? yo creo que sí pues con un poquito de carácter todo se consigue y los aires franceses han robustecido mucho mi fuerza de voluntad. (Ávila Hernández, 2010, p.57)

Por otro lado, cabe resaltar la manera en que la revista se involucró con las artes plásticas por medio de un evento con los pintores mexicanos, suceso que marca una voluntad que hasta entonces no se había visto en el ambiente literario mexicano, así como un interés por el arte de los directores, el cual expresó Cravioto por medio de estudios y conferencias en los años postreros, y Castillo Ledón cuando dirigió el Museo Nacional. Dice Ávila Hernández:

se muestra un empeño colectivo, grupal, por lo que reconozco en estos pioneros del reconocido Ateneo de la Juventud, su ahínco por colaborar en la construcción y desarrollo del arte, ámbito que carecía de oportunidades, de desarrollo: esa inquietud llevó a todos sus participantes a buscar mejores opciones, no sólo para su interés particular, sino para la consagración nacional. (Ávila Hernández, Luis Castillo Ledón, p.108) ${ }^{7}$

A la muerte de la revista, después de cinco números, los jóvenes no estaban dispuestos a abandonar la escena, pues si Savia Moderna les había servido como un primer espacio para darse a conocer como un nuevo contingente, también existía una clara conciencia por parte de algunos miembros sobre la necesidad de hacerse de otras plataformas de expresión. Es por eso que, después de un breve descanso, a principios de 1907, tanto los directores como los demás colaboradores de la revista migraron las "oficinas" a la casa de dos pares de hermanos: Max y Pedro Henríquez Ureña e Ignacio y Luis Castillo Ledón, ubicada en la planta baja del número 4 de la calle siete de Soto, en la colonia Guerrero (Henríquez Ureña, Memorias, pp.113-114). Lugar que fue, junto con la casa de Alfonso Reyes, la biblioteca de Antonio Caso y el taller de Jesús T. Acevedo, un espacio donde la actividad intelectual floreció. Fue este último el que propuso crear

\footnotetext{
${ }^{7}$ La relación entre la revista y el arte ha sido estudiada en detalle por la crítica literaria, se pueden consultar algunos estudios como: Ateneo de la juventud y la plástica mexicana; Virginia Medina Ávila, "El Ateneo de la juventud y el arte: los pintores ateneístas y la revista Savia Moderna" (2011, pp.77-88), y Nicola Colby, La construcción de una estética: el Ateneo de la Juventud, Vasconcelos y la primera etapa de la pintura mural posrevolucionaria (1921-1924).
} 
la Sociedad de Conferencias, proyecto que se dilató por la indignación que causó la segunda vuelta de Revista Azul a cargo de Manuel Caballero.

"La Protesta Literaria", manifiesto con el cual la juventud se alza y hace frente a la publicación de Manuel Caballero, lo hace a nombre de Manuel Gutiérrez Nájera y lo que su figura representa en la literatura mexicana, pues Caballero había tomado el nombre de la revista del Duque Job y, contradictoriamente, había lanzado un prospecto en el cual atacaba la estética modernista del que este último fue un pilar fundamental. El manifiesto fue escrito por Castillo Ledón, como corrobora Ávila Hernández al encontrar el original en su archivo. Sin embargo, el tono beligerante se puede atribuir a Cravioto, que tenía más experiencia en estos avatares, y que acababa de llegar de Europa para el enfrentamiento y firma al calce. Incluso en este episodio paradigmático en la formación del Ateneo de la Juventud se pueden encontrar huellas precisas de los directores de Savia Moderna. Sobre esto, un no tan convencido Pedro Henríquez Ureña apunta: "los manifiestos son documentos de combate en los que no es posible aspirar a la perfección. Éste tiene claridad y energía, y eso basta" (Henríquez Ureña, Memorias, p.26). Sobre ello Gabriel Zaid dice que este acto fue el pretexto para "tomar la calle, salir a la vida pública y decir: aquí estamos, miren la fuerza que tenemos, el talento que tenemos, la razón que tenemos" (1997, p.86). La pléyade que alguna vez estuvo bajo la dirección de Cravioto y Castillo Ledón daba forma a su movimiento, la juventud reclamaba su lugar. La empresa de Caballero cedió a los seis números después del prospecto. La lucha que cimbró el ambiente literario había terminado. ${ }^{8}$ No obstante, los proto-ateneístas, todavía con el impulso fresco de estos eventos se lanzaron a concretar el proyecto que habían postergado desde enero: las conferencias. Lanzaron dos series de conferencias, que tenían por propósito situarse como especialistas sobre temas de literatura y filosofía, principalmente, y aprovechar la situación para posicionarse como figuras intelectuales de referencia. Los directores de Savia Moderna participaron en estas series tras bambalinas, es decir en la organización de los eventos, y no como protagonistas. Sin embargo, cabe destacar que entre la primera y la segunda conferencia del segundo ciclo se llevó a cabo el homenaje a Gabino Barreda el 22 de marzo de 1908 en el Teatro Arbeu. La Sociedad de Conferencias participó en dicho evento, con un estilo que Cravioto conocía por sus asociaciones liberales: usar los eventos públicos del régimen, para desde ahí, atacarlo. ${ }^{9}$ Un año después, en noviembre de 1909, se redactaron los estatutos del Ateneo de la Juventud, del cual ambos, Luis Castillo Ledón y Alfonso Cravioto, fueron miembros fundadores.

Por este tiempo es cuando se da por terminada la etapa poética de los dos directores de Savia Moderna, que se volcaron por intereses particulares, ya dibujados con anterioridad: la historia, el arte y la política. Castillo Ledón hizo su parte desde el Museo Nacional que después fue Museo Nacional de Arqueología, Historia y Etnografía, enfocándose sobre todo en la historia. Ya desde 1907 había hecho reflexiones sobre la novela, usando como pretexto la de su compañero, Carlos González Peña, titulada La Chiquilla. Proyecto que tomó una forma más elaborada en 1922, bajo el título: Orígenes de la novela en México, editada por el Museo Nacional. A la par de las conferencias, colaboró en una Bibliografía Histórica Mexicana (1908), y para el festejo del Centenario de la Independencia fue comisionado para recorrer El Itinerario de Hidalgo, proyecto que lo consagraría como historiógrafo, y ruta a la que debemos

${ }^{8}$ Para seguir esta polémica es indispensable consultar el libro de Fernado Curiel Defossé, Tarda necrofilia. Itinerario de la segunda Revista Azul, pues ahí además de reproducir la edición facsimilar, agrega una buena cantidad de documentos que reflejan el estado belicoso de la contienda entre los jovenes y el periodista.

${ }^{9}$ Para un estudio de las implicaciones de la participación de los jóvenes en este evento ver: Alejandra Pita González y Marco Antonio Vuelvas Solórzano "La conformación de una genealogía intelectual” (2013, pp.17-37). 
Uno de los más significativos fondos documentales, en el contexto del Bicentenario de la Independencia [...] una colección de 541 impresiones fotográficas estereoscópicas y otras de formato $4 \times 5$. Imágenes captadas por el fotógrafo Gustavo F. Solís, a solicitud del periodista, historiador y político mexicano Luis Castillo Ledón (1879-1944). Ambos recorrieron cerca de doce mil kilómetros siguiendo el itinerario del cura Miguel Hidalgo y Costilla. (García Prado, FLCL)

Viaje que concluyó en un texto llamado: Hidalgo. La vida del héroe, trabajo que el nayarita siguió complementando, para en la década de los treinta sacar un segundo volumen.

Por su lado, por el mismo tiempo, cuando la reelección de Porfirio Díaz es inminente, la chispa beligerante que Alfonso Cravioto mostró en Pachuca cobró nuevamente vida. La Revolución fue un escenario en el que pudo realmente sobresalir, aunque fuera de manera crispada y con entradas a la prisión, junto con Jesús Urueta, otro ateneísta. Pues su habilidad política le permitió ayudar en la constitución del 17 (donde tomó parte importante en la concepción de los artículos 3 y 123) al tiempo que podía dar cobijo a algunos compañeros ateneístas, entre ellos, el mismo Castillo Ledón. Fue gracias a esta habilidad que a lo largo de su carrera política se desempeñó en diversos puestos gubernamentales, los cuales aprovechó para impulsar desde diferentes frentes ideas que consideró de valía.

El sendero que ambos comenzaron a recorrer después de la primera década del siglo XX estuvo en total consonancia con sus primeros años, y aunque al parecer alejados de la vena literaria de su juventud, centrándose uno en la historia y otro en la política, nunca desatendieron el desarrollo cultural y todo aquello que esto implicaba; pues, después de todo, emplearon las estrategias que el grupo ateneísta fue desarrollando para impulsar, desde diferentes aristas, el progreso cultural. Desde las instituciones por las que fueron migrando con el tiempo, consecuencia de la Revolución, y con el estatus de intelectuales que habían adquirido gracias a las empresas que habían dirigido, se fueron abrieron paso a otros puestos que no dudaron en utilizar para un bien común; por ejemplo, el desarrollo de la educación.

Tal vez ese sea el mayor distintivo de estos dos ateneístas: un emigrar que les permitía dar cobijo y guía a sus compañeros. Atributo que no menguó con los años y que vale para considerarlos más que directores de una sola empresa, sino como directores de una pléyade de escritores que a pesar de tomar caminos propios -a veces incluso encontrados- fue arropando nuevos escritores e intelectuales ${ }^{10}$ y que, a la par, resignificó la manera de concebir la literatura y la cultura en México.

${ }^{10}$ Un ejemplo de esta afirmación se puede apreciar con el estridentista Manuel Maples Arce, que llegó recomendado por el pachuqueño a Veracruz en la segunda mitad de los años veinte, o bien con Agustín Yañez que estuvo al frente del Instituto del Estado, en Nayarit, por recomendación del entonces Gobernador Castillo Ledón en los años treinta. 


\section{Referencias Bibliográficas}

Ávila Hernández, J. (2005). "Savia Moderna. Frontera entre siglos". La República de las letras. Asomos a la cultura escrita del México Decimonónico (265-277). México: UNAM. . (2010). Luis Castillo Ledón (1879-1944), de Savio a historiógrafo ateneísta 19061911. Tesis de maestría en Historia dirigida por Fernando Curiel Defossé. México: UNAM.

Castillo Ledón, L. (1906). “Amor-materia”. Savia Moderna [edición facsimilar]. Número 1: 44. . (1906). "La familia joyeuse”. Savia Moderna [edición facsimilar], (2), 141-142. . (1906). “Almas que pasan [Reseñas]”. Savia Moderna [edición facsimilar], (3), 219222.

. (1906). "Presentimiento". Savia Moderna [edición facsimilar], (4), 270-271.

Clark de Lara, B., y Zavala Díaz, A. (2002). La construcción del modernismo (antología). México: UNAM.

Clark de Lara, B. y Curiel Defossé F. (coordinación e introducción). (2002), Revista Moderna de México (1903-1911) II. Contexto. México: UNAM.

Colby, N. (1985). La construcción de una estética: el Ateneo de la Juventud, Vasconcelos y la primera etapa de la pintura mural posrevolucionaria (1921-1924). Tesis de maestría. México: UNAM.

Cravioto, A., y Lechuga, M. (1901). "Protesta". Regeneración. Periódico Independiente de combate [edición facsimilar], tomo II: 50.

. (1906). "Invocación". Savia Moderna [edición facsimilar], (1), 30-32.

. (1906). "Los que se van. Baltazar Muñoz Lumbier”. Savia Moderna [edición facsimilar], (1), 65-68.

. (1906), “El dolor”. Savia Moderna [edición facsimilar], (2), 115-118. (1906), "Sensaciones de viaje". Savia Moderna [edición facsimilar], (4), 233-240.

Cravioto, M. (2009). "Alfonso Cravioto: El ser bajo la ficción del personaje”. Elena Madrigal Rodríguez et al. (ed.). Tema y Variaciones de Literatura: a cien años del Ateneo de la Juventud. México: UAM-A, (33, semestre II), 205-240.

Curiel Defossé, F. (1996). "El Ateneo Modernista”. Revista de Literatura Mexicana. México: UNAM, Volúmen. VII (1), 39-59.

. (1996). Tarda necrofilia. Itinerario de la segunda Revista Azul. México: UNAM, [incluye facsímil].

. (1998). La revuelta. Interpretación del Ateneo de la Juventud (1906-1929). México: UNAM. . (2001). Ateneo de la Juventud (A-Z). México: UNAM.

García Prado, M. V. (Sf). Fondo Luis Castillo Ledón. Paso por paso la Ruta de la Independencia. Sin datos.

Granados Chapa, M. A. (1984). Alfonso Cravioto, un liberal hidalguense. México:

Océano/Gobierno del Estado de Hidalgo.

Henríquez Ureña, M. (1978). Breve historia del modernismo. México: FCE.

Henríquez Ureña, P. (2000). Memorias/Diario/Notas de viaje. Introducción y notas de Enrique Zuleta Álvarez. México: FCE.

Mauleón, H. (2006). “Cien años de Savia Moderna”. El Universal. México (24 de junio), Confabulario. 
Medina Ávila, V. (2011). "El Ateneo de la juventud y el arte: los pintores ateneístas y la revista Savia Moderna". Multidisciplina, (10), 77-88.

Oviedo, J. M. (2001), Historia de la literatura hispanoamericana. Del Romanticismo al modernismo. Madrid: Alianza Editorial.

Pascual Gay, J. (2012). El beso de la quimera. Una historia del decadentismo en México (18931898. San Luis Potosí: El Colegio de San Luis.

. Fuente Ballesteros, R., y Isabel Ramírez, M. (2014). Historias de las revistas literarias mexicanas (1894-1946): de El Renacimiento a las revistas modernistas (1894-1911). Pascual Gay, J., y Jalife, A. (coords.). San Luis Potosí: El Colegio de San Luis.

Pita González, A., y Vuelvas Solórzano, M. A. (2013). "La conformación de una genealogía intelectual. El homenaje a Gabino Barreda (1908)". Historia y Espacio, (41) agostodiciembre, 17-37.

Quintanilla, S. (2008). Nosotros. La juventud del Ateneo de México. México: Tusquets.

Quirarte, V. (2001). "Prólogo". Prólogo, edición y notas de Quirarte, V. Jesús E. Valenzuela. Mis recuerdos. Manojos de rimas. México: CNCA.

Reyes, A. (1960). "Pasado Inmediato". Obras Completas. Tomo XII. México: FCE.

Sánchez Pineda, Ernesto. (2014). "La Revista Azul contra los modernistas. La segunda vuelta". Edición de Claudia López Pedroza y Juan Pascual Gay. Literatura y prensa periódica. Historias de una intimidad, 99-115. San Luis Potosí: El Colegio de San Luis, . (2017). "La toma de un espacio. La Revista Moderna de México y los ateneístas". Marco Antonio Chavarín González e Yliana Rodríguez González (Coords.). Literatura y prensa periódica mexicana. Siglos XIX y XX. Afinidades, simpatías, complicidades, 239258. San Luis Potosí: COLSAN.

S/f. (1987). Revista Moderna. Arte y Ciencia [edición facsimilar]. 5 volúmenes. Prólogo de Julio Torri, estudio introductorio de Héctor Valdez. México: UNAM. . (1901). "Al público". Regeneración, (54) 16 de septiembre. . (1903). "Nuestros compañeros en Belém. El Hijo del Ahuizote, (848) 26 de abril, 234235.

Varios. (2010). Ateneo de la juventud y la plástica mexicana. México: INBA/CONACULTA. . (1901). Regeneración, (52) agosto.

Vergara Hernández, A. (2011). "Los masones y la Revolución Mexicana en el estado de Hidalgo". CINTEOTL, Revista de Investigación en Ciencias Sociales y Humanidades, (13) enero-abril, 12-13.

Zaid, G. (1997). Tres poetas Católicos. México: Océano. 